\title{
FACTORS IN THE PATHOGENESIS OF PEPTIC ULCER

\author{
The Present Basis of Treatment
}

J. E. Lennard-Jones, M.A., M.B., M.R.C.P.

Medical Research Council Department of Clinical Research, University College Hospital Medical School, London, W.C.. \&

Although the ground is strewn with tantalizing clues, each contributing to an advance in understanding of this disease, no single answer to the problem of peptic ulcer has been found. Almost certainly many factors conspire to produce each ulcer and the most important factor differs from patient to patient.

It is likely that acid-pepsin is always a factor in the production of an ulcer and no benign ulcer has so far been reported in the presence of complete achlorhydria. In some patients who secrete large quantities of acid, as in the Zollinger-Ellison syndrome to be discussed later, this hypersecretion is probably responsible for the ulceration. However; most patients with gastric ulcer and many patients with duodenal ulcer secrete acid in normal amounts and at a normal rate. In a few patients with gastric ulcer it may even be difficult to demonstrate the secretion of any acid ${ }^{81}$ though some acid is always found. In Fig. I are seen results obtained with a single test of acid secretion; the general findings are similar whatever test is used. Patients with duodenal ulcer tend as a group to secrete more acid than normal and many secrete acid above the upper limit of the normal range: patients with gastric ulcer differ little from normal. Similar results are also found when pepsin is studied. Fig. 2 shows measurements of urinary pepsinogen, thought to be a measure of peptic cell mass, and the relationship between the three groups of subjects is seen to be the same as with acid secretion.

These wide differences in acid secretion have led to a concept of a balance of forces, acid-pepsin challenging the defensive forces of the mucosa. As in war, a very powerful attack may prove irresistible; a weak attack succeeds only if the defences are unusually vulnerable. This article reviews some of the factors known to influence this balance of forces and the way in which they can be modified by treatment.

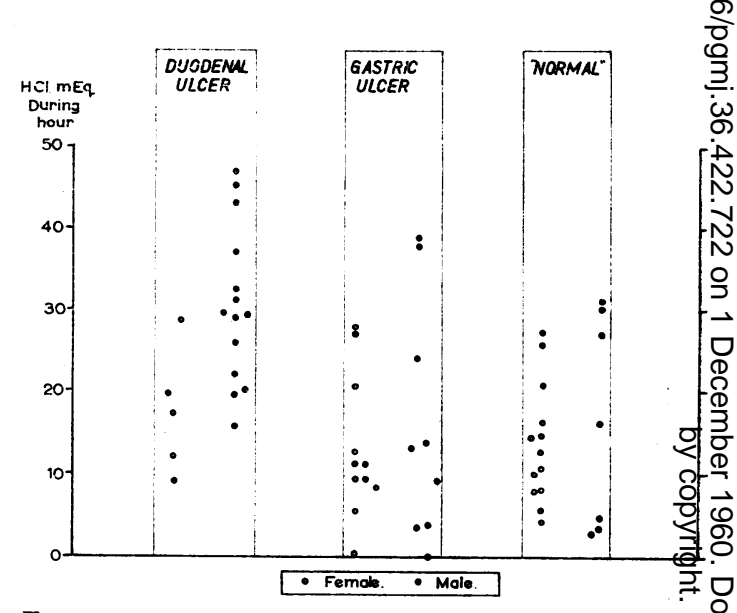

FIG. I.-Results of the ' augmented' histamine test is a consecutive series of patients with duodenal ulce 5 and gastric ulcer compared to the findings in patients with gastro-intestinal disease not involving the stomach. (Connell, Lennard-Jones and Wile cox, unpublished data.)

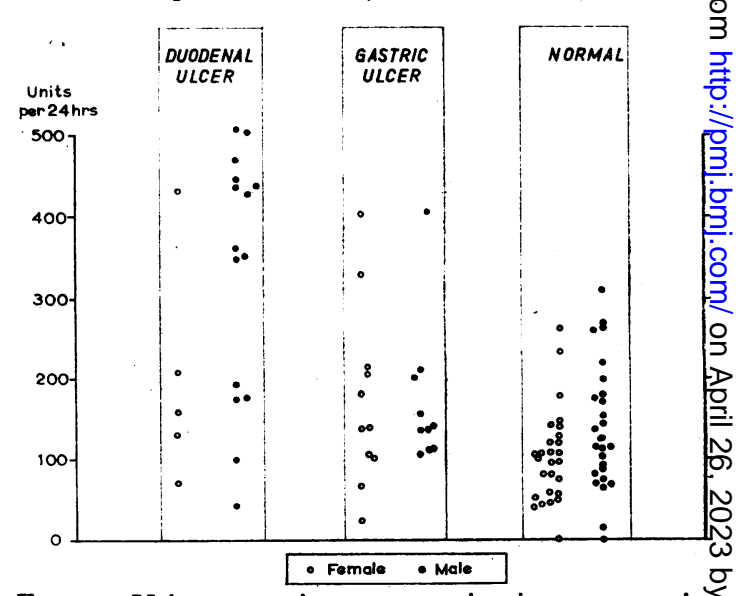

FIG. 2.-Urinary pepsinogen excretion in a consecutiv series of patients with duodenal ulcer and gastric ulcer, compared to the findings in a group of normal subjects. (Connell, Lennard-Jones and ${ }^{+}$ Wilcox, unpublished data.) 


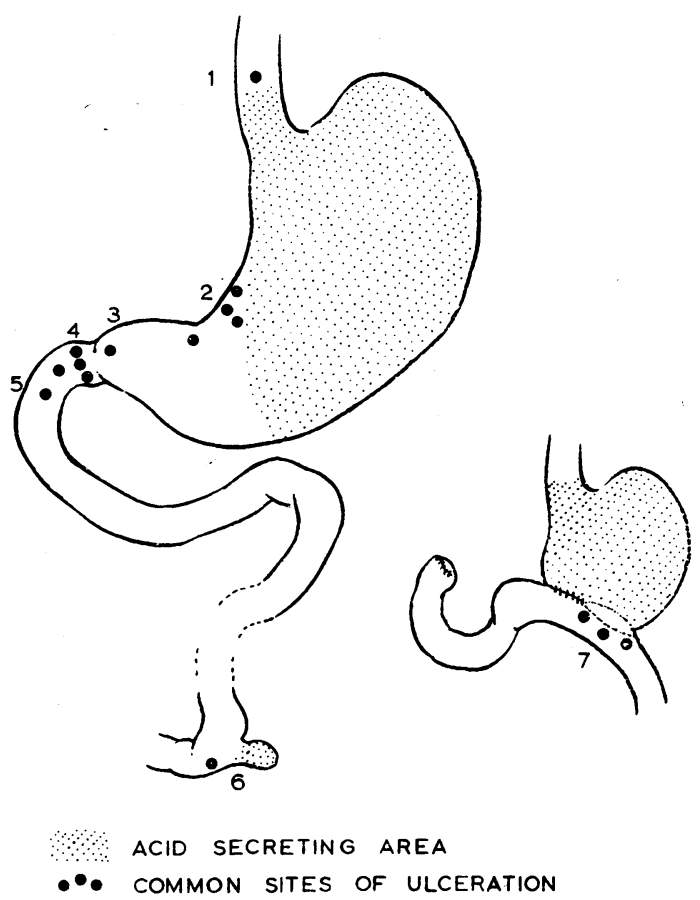

FIG. 3.-Peptic ulceration tends to occur adjacent to acid-secreting gastric mucosa: (1) oesophageal ('Barrett') ulcer; (2) gastric ulcer; (3) pre(juxta-) pyloric ulcer; (4) duodenal ulcer; (5) postbulbar duodenal ulcer; (6) ileal ulcer adjacent to heterotopic gastric mucosa in a Meckel's diverticulum; (7) jejunal (stomal) ulcer near anastomosis with the stomach.

\section{Anatomical Factors}

The sites at which peptic ulcers tend to occur are shown in Fig. 3. Barrett ${ }^{4}$ pointed out that two types of lesion occur in the oesophagus-reflux oesophagitis, which is due to the action of acid on squamous epithelium and may lead to stricture formation, and, rarely, a typical chronic peptic ulcer ('Barrett ulcer') occurring in gastric-type mucosa which is continuous with the mucosa of the stomach and extends for a variable distance up the oesophagus.

The commonest sites of peptic ulceration lie along the lesser curve of the stomach, in the gastric antrum and in the first part of the duodenum. The lesser curve of the stomach and the pyloric antrum form the gastric canal, along which food (and probably acid) flows; the fundus and body of the stomach act as a storage organ. The mucosa of the fundus and body of the stomach contains straight tubular glands in which are situated the acid and pepsin-secreting cells. The pyloric antrum is lined by a flatter mucosa containing coiled glands which secrete an alkaline juice containing mucus. In the region of the pylorus, the histological appearance changes sharply and the coiled Brunner's glands of the duodenum, situated mainly in the submucosa, are found. Oi and his colleagues ${ }^{64,65}$ have shown that the site of junction between the acid-secreting fundic mucosa and the pyloric mucosa varies con- $c$ siderably from person to person. On the lesser curve the border zone (about $2 \mathrm{~cm}$. wide) varied $\stackrel{5}{\rightarrow}$ between 0 and $16 \mathrm{~cm}$. from the pylorus: in many $\bar{O}$ patients, therefore, pyloric mucosa occupied much $\underline{\bar{\sigma}}$ of the lesser curve. The junction between pyloric $\frac{\bar{s}}{\sigma}$ and duodenal mucosa was situated within $5 \mathrm{~mm}$. $\stackrel{\mathbb{\Omega}}{\Omega}$ of the summit of the pyloric sphincter.

These authors examined the position of peptic $\stackrel{\text { s }}{\rightarrow}$ ulcers in relation to the junction of different types of mucosa. They found that all gastric ulcers $\vec{\omega}$ occurred in pyloric mucosa and that, when a $\frac{\sigma}{\circ}$ duodenal ulcer was not present, the proximal edge $\bar{C}$ of the ulcer was within $2 \mathrm{~cm}$. of the border zone 3 . between fundic and pyloric mucosa. Every $\omega_{\sigma}$ duodenal ulcer was situated in the duodenal mucosa, usually within $2 \mathrm{~cm}$. of its junction with $\mathrm{N}$ the pyloric mucosa. Gastric ulcers associated $N$ with duodenal ulcer all occurred in pyloric $N$

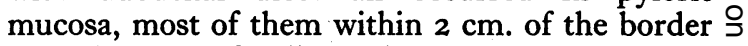
zone between fundic and pyloric mucosa, but $\rightarrow$ about one in six was situated in the pyloric gland $\overparen{D}$ area more than $2 \mathrm{~cm}$. from the border zone. It $\mathbb{\mathbb { D }}$ appears from these observations that the pyloris mucosa and duodenal mucosa are most vulnerable $\stackrel{\mathbb{Q}}{-}$ or subjected to the heaviest attack at their neares $\vec{\theta}$ point to the fundic mucosa. Similarly, jejuna ulcers form just distal to an anastomosis with the stomach and ileal ulcers form just distal to $\vec{a}$ Meckel's diverticulum containing gastric mucosa.

\section{Constitutional Factors}

Taken as a whole, peptic ulcers occür more $\stackrel{\mathbb{Q}}{\varrho}$ frequently in men than in women. In a large $\overrightarrow{\overrightarrow{0}}$ autopsy series, conducted as a prospective in- 3 vestigation into the frequency of peptic ulcer, ${ }^{82}$ duodenal ulcers were found among patients dying of other causes twice as commonly among men as among women, whereas gastric ulcers were found incidentally with equal frequency in the two sexes. The predominance of duodenal ulcers in men is greatest below the age of 45 ; after this the gap between the sexes rapidly narrows. Gastric ulcer is also commoner among young men than young women but in later life the sex ratio is reversed. $\frac{T}{2}$ Deaths from ulcer follow the same trend: there are six to eight times as many deaths from ulcer $N$ among younger men as there are among women of $N$ the same age groups; over the age of 65 years there is little difference between the sexes.

It has frequently been observed that peptic ulcer tends to run in families. Doll and Buch ${ }^{21}$ have $\stackrel{\circ}{\circ}$ shown that the siblings and father of a patient $\Phi$ with peptic ulcer have a significantly greater risk + of developing an ulcer than the relatives of a 
control population. This excess among the relatives of a patient with a gastric ulcer is almost entirely due to an excess of gastric ulcers, and similarly with duodenal ulcer, ${ }^{23}$ so that gastric and duodenal ulcers must be regarded as mainly independent from the point of view of heredity. This study does not exclude the effects of similar environmental factors in the same family but it seems unlikely that these factors are as important as constitutional factors.

Only two inherited characteristics have so far been observed which are associated with the occurrence of peptic ulcers. These factors are a patient's ABO blood group and the presence or absence in his saliva and other secretions of the ABH blood group substances. Work in many different countries ${ }^{68}$ has shown that people of blood group $\mathrm{O}$ have a greater likelihood (about I.4 : I) of developing a duodenal ulcer, and to a lesser extent a gastric ulcer, than people of Groups A, B or AB. The increased risk associated with Group $O$ is not apparent among siblings, an intriguing fact which is so far unexplained. ${ }^{14}$ The association of Group $O$ with stomal ulcer is greater than the association with duodenal ulcer, patients of blood group $\mathrm{O}$ developing this complication about 1.8 times more often than patients of other groups. ${ }^{28}$ So far there is no evidence that the severity of duodenal ulcer, as judged by the age of onset or the necessity for surgical treatment, is related to blood group. ${ }^{28}$

The A, B and $\mathrm{H}$ blood group substances may be secreted into the saliva and other secretions (H-substance is present in the tissues of people of all blood groups and is apparently independent of the ABO system). People who do not secrete these substances, ' non-secretors', have an increased liability to duodenal ulcer and this liability is independent of the blood group. This finding suggests that the relative immunity of people of groups A and B to ulceration does not depend on the presence of these substances in the secretions; if this were so there should be no increased risk of duodenal ulceration among Group $O$ non-secretors compared to non-secretors of groups $\mathrm{A}$ and $\mathrm{B}$. Non-secretors of Group $\mathrm{O}$ have the greatest risk of developing a duodenal ulcer, about 2.5 times the risk for secretors of the other groups. ${ }^{14}$ Using the fluorescein-labelled antibody technique, Glynn and his colleagues ${ }^{33}$ have shown the distribution of blood group substances in the gastric and duodenal mucosa. In the stomach, the superficial layers of the body always contain $\mathrm{H}$-substance; A-substance is present in the superficial and deep layers in Group A secretors but absent in the superficial layers in non-secretors. In the duodenum, the findings are similar as regards A-substance but there is an important difference in that $\mathrm{H}$-substance is not always present. This difference between the stomach and duodenum may be related to the more marked association of blood group $\mathrm{O}$ and non-secretion with duodenal ulcer than with gastric ulcer.

\section{Environmental Factors}

There seems little doubt that the incidence of duodenal ulcer has increased during this century. Further, acute gastric ulcers in young women are now rare whereas they used to be common. ${ }^{3,50}$ These facts suggest that important environmental factors are affecting the incidence of peptic ulcer.

The best-documented environmental factor is tobacco. In a prospective controlled investiga$\operatorname{tion}^{27}$ there were significantly fewer non-smokers among patients with peptic ulcer than among a matched control group. Among smokers, the group with gastric ulcer contained significantly more subjects who smoked cigarettes only, as opposed to pipe smoking, than the control group, and also in this group there was a higher proportion of men who began to smoke before the age of $I_{5}$ years than in the control group. In a therapeutic trial, referred to later, the crater of gastric ulcers decreased in size more quickly among smokers who accepted advice to stop smoking than among smokers who were not advised to stop smoking or who responded to advice to stop by merely reducing their consumption.

Aspirin may be a factor in the production of peptic ulcers. This is suggested by the association of haematemesis and melaena with the taking of this drug. 2

Any association between a particular diet and peptic ulceration is very difficult to assess. It seems likely that the notable difference in ulcer frequency in different parts of India can be partly attributed to different diets, but other factors may also be operating. Therapeutic trials have not justified the place of special diets in the treatment of ulcer. ${ }^{25,26,80}$ In an investigation into a possible association of food temperature with abnormalities of the gastric mucosa Edwards and Edwards ${ }^{30}$ found that patients over 30 years of age with an abnormal gastric mucosa drank tea $5-6^{\circ}$ hotter than those with a normal mucosa, a correlation of statistical significance.

Psychological factors have been widely blamed for the increased incidence of duodenal ulcer and it is common clinical experience that overwork or worry may lead to an exacerbation of symptoms from a pre-existing chronic ulcer. Evidence as to whether psychological factors are important in the causation of ulcer is difficult to gather. Davies and Wilson ${ }^{20}$ showed that symptoms of peptic ulceration began in $84 \%$ of patients soon after some event affecting their work or finances or the 
health of their family: only $22 \%$ of a control series of patients with hernia gave a history of any such event preceding their illness. Many more of the ulcer patients showed evidence of undue mental tension, long antedating their ulcer symptoms, than the control group. Kellock ${ }^{52}$ compared possible childhood factors such as place in the family, separation from parents and serious illness in a group of 250 men with duodenal ulcer and a matched control group and found no difference between the two groups in any factor he examined. It has been observed that duodenal ulcer is commoner than would be expected among certain occupations, notably foremen and business executives, whereas it is less common than would be expected in others, for example farm labourers. ${ }^{22}$ The authors think that this is a real difference and not due to different standards of diagnosis, a factor which possibly accounts for the increased frequency of duodenal ulceration observed in doctors. Whether the increased incidence in certain occupations is due to the 'stress' of work or to other factors is unresolved.

\section{Acid and Pepsin}

It is generally agreed that acid-pepsin is the aggressive agent in the production of ulcers. Ulceration may come about because more acid than normal is secreted, or because the acid is in contact with the mucosa for longer than usual, or because acid comes into contact with particularly vulnerable mucosa. Usually a combination of these factors is operating; the first two and the part played by pepsin will now be considered separately.

\section{(a) Acid Secretion is Excessive}

Cox, ${ }^{18}$ in a classical study on autopsy material, showed that the stomachs of patients with duodenal ulcer are heavier, that the mucosa is thicker and that the absolute number of parietal cells is greater then normal. In the next year, $\mathrm{Kay}^{51}$ introduced an ' augmented histamine test'. This test is made possible by the fact that antihistamine drugs block the unpleasant peripheral effects of histamine but do not prevent stimulation of the stomach. A dose-response curve to histamine can be constructed and that dose given which causes ' maximal ' secretion, the juice being collected by continuous aspiration. It has been shown ${ }^{10}$ that this test provides a good measure of the number of parietal cells present. Using this test, a group of patients with duodenal ulcer is found to secrete on average more acid than normal and a group of patients with gastric ulcer differs little from normal (Fig. I). Whether the difference in numbers of parietal cells is constitutional or acquired is unknown.
There is good evidence that the maximum concentration at which the stomach can secrete acid is $\cong$ about I 55 millinormal.46 Lower concentrations 3 can be secreted and this is probably due to ad- $\mathbb{Q}$ mixture of acid secreted by the parietal cells with $C$ a 'non-parietal' secretion. After secretion, acid $\underset{\vec{D}}{\vec{D}}$ is neutralized and buffered by saliva, regurgitated duodenal contents and food. The concentration of acid in the stomach can be estimated by measuring the $\mathrm{pH}$ of samples of gastric contents withdrawn at intervals throughout the 24 hours. ${ }^{45}$ Using this technique, it has been shown that the mean कs duration of high acidity in patients with duodenal $\vec{\circ}$ ulcer was significantly greater than normal, whereas the mean duration of low acidity was significantly greater than normal in patients with gastric ulcer.

Acid is normally secreted at meal times and inhibitory mechanisms act when the gastric antrum contains acid and when acid reaches the duodenum. Patients with duodenal ulcer differ from normal in that acid secretion tends to continue under basal conditions and at night. ${ }^{54,55}$ Much work and thought has centred around the cause of this excessive basal and nocturnal secretion in patients with duodenal ulcer. It might be that a fixed proportion of the parietal cell population secretes under resting conditions; if there are more cells, as there tend to be in patients witlo duodenal ulcer, there would be a higher basa secretion. This hypothesis was favoured by Hunf. and Kay. ${ }^{41}$ However, recent work ${ }^{\mathbf{7 1}}$ suggests that this is too simple an explanation: the basal secretion forms an increasing proportion of the ' maximal' secretion.

The large resting secretion could be, partly or wholly, psychologically determined. Shay et al. ${ }^{\mathbf{7 0}}$ have demonstrated the rise in basal secretion which occurs during a distressing psychiatric interview and the conditioned reflex which can develop as the test is repeated. ${ }^{73}$ This increased secretion may be mediated by a humoral mechanism for, in the observations referred to, it occurred about three hours after the interview. By analogy with insulin stimulation, this time lag suggests adrenal stimulation. The observation that vagotomy reduces basal and nocturnal secretion does not prove that secretion under these conditions is nervous in origin because evidence is accumulating that vagotomy also impairs the secretory response to humoral and histamine stimulation. ${ }^{32}$ In dogs humoral secretion only occurs in a denervated pouch if a cholinergic drug is given. ${ }^{36}$

The excessive inter-digestive secretion might be the result either of excessive humoral stimulation or lack of humoral inhibition. ${ }^{17}$ Dragstedt ${ }^{29}$ and his colleagues have demonstrated that the presence of the gastric antrum is necessary for 
normal gastric secretion by Heidenhain pouches in dogs. An intact antrum is also necessary for normal secretion in man. ${ }^{32}$ In the dog, acid secretion occurs in a Heidenhain pouch if neutral food is placed in a transplanted antral pouch or if the antral pouch is distended. Experimental duodenal or stomal ulcers, associated with hypersecretion, uccur in the dog if an antral pouch is transplanted to the colon. Acid secretion is inhibited if an antral pouch is distended with an acid solution. Acid in the duodenum also inhibits gastric secretion and this inhibition depends, in the dog, on intact vagi. ${ }^{16}$ The inhibiting agent arising from the duodenum may be identical with, or closely related to, secretin. ${ }^{29}$

The place of histamine in normal gastric physiology is debatable; the subject has been reviewed by James. ${ }^{46}$ Histamine is present in the mucosa of the gastro-intestinal tract and more is present in the fundus of the stomach than in the pyloric region. Histamine is also present in gastric secretion, however stimulated. Gastrin can be prepared free from histamine and the two substances do not appear to be identical. ${ }^{35}$ Recent work in man has shown that the stimulating effect of histamine can be partly blocked by anticholinergic drugs, suggesting that histamine acts, at least in part, through nervous tissue. ${ }^{12,59}$ Histamine in small quantities is normally absorbed from the intestinal tract into the portal blood; part is inactivated in the liver and the remainder is rapidly excreted in the urine. If the liver is bypassed by porto-caval anastomosis in dogs, ingested histamine can be shown experimentally to induce gastric secretion in denervated gastric pouches. ${ }^{43}, 44$ It is possible that absorbed histamine may cause gastric hypersecretion in some patients with liver disease.

Other substances which may play a part in the humoral control of gastric secretion are 5-hydroxytryptamine, which is present in the argentaffin cells of the gastro-intestinal mucosa, and its precursor, 5-hydroxytryptophan. Both these substances inhibit histamine-stimulated secretion under experimental conditions. ${ }^{7,} 8$

The finding of a gastrin-like substance in the pancreatic adenoma of a patient with the ZollingerEllison syndrome, ${ }^{37}$ as described below, opens a new field of enquiry into the humoral control of secretion.

\section{(b) Prolonged Retention of Acid in the Stomach}

Two theories have been put forward to explain the occurrence of gastric ulceration when gastric emptying is delayed. Dragstedt ${ }^{29}$ has suggested that the prolonged contact of food with the antral mucosa leads to increased humoral stimulation of the stomach by gastrin and has put forward experimental evidence to support this view. Johnson ${ }^{48,49}$ has suggested that it is the prolonged presence of acid in the antrum that does the harm.

\section{(c) Pepsin}

The proteolytic enzymes in gastric juice have recently been investigated at less acid $\mathrm{pH}$ values than previously. In normal people two maxima are commonly found at $\mathrm{pH}$. .6 to 2.4 and $\mathrm{pH} 3.3$ to 4.0 , varying in different individuals and with different substrates. ${ }^{75}$ A little proteolytic activity can also be demonstrated with a maximum at $\mathrm{pH} 6.8$ to $7.2 .^{76}$ Patients with peptic ulcer differ in that three maxima are commonly present at $\mathrm{pH} \mathrm{I.5}$ to $2 . \mathrm{I}, 2.5$ to $3 . \mathrm{I}$ and 3.3 to $3.8 .{ }^{77}$ These three maxima were observed in 7 of 11 patients with peptic ulcer but in only 2 of 25 normal subjects. It seems possible that peptic ulceration may occur more readily in the small group of normal subjects who digest proteins at three maximum $\mathrm{pH}$ values than in the remainder of the population. This work is also of great importance because up to now it has often been assumed that maximum proteolytic activity occurs at about $\mathrm{pH} \mathrm{2.5}$; the aim in therapy has therefore been to reduce acidity below this level. It now appears that gastric proteolysis may occur readily at $\mathrm{pH} 3.5$ to 4.5 .

The stimulus to pepsin secretion has not been clearly defined: it is probably mainly nervous. ${ }^{46}$ There was a correlation between acid secretion and pepsin secretion (measured at $\mathrm{pH}$ 2.I) in pectin ? test meals. ${ }^{40}$ The concentration of pepsin (measured at $\mathrm{pH}$ I.5) in gastric juice secreted at night or during insulin hypoglycaemia in patients with duodenal ulcer did not differ from that in control subjects, but the volume and acidity of the juice was increased in the ulcer patients. ${ }^{11}$ This suggests that the amount of pepsin secreted depends on the secretory cell mass. It is widely believed that the urinary excretion of pepsinogen, which tends to be raised in patients with a duodenal ulcer (Fig. 2), also depends on the peptic cell mass.

\section{Hormonal Factors}

The relative immunity of women to peptic ulceration before the menopause has been discussed already: women also seem to be especially free from the symptoms of an established ulcer during pregnancy. ${ }^{13}$ These and other observations suggest that oestrogens may protect against peptic ulceration. This concept is supported by the beneficial effect, demonstrated in a recent controlled therapeutic trial, ${ }^{80}$ of stilboestrol in the treatment of men with duodenal ulcer.

In discussing adrenal hormones, it is important to separate the role of the adrenal in normal physiology from the possible role of the adrenal 
under conditions of stress, or the clinical situation in which large therapeutic doses of corticosteroid drugs are given. Porter et al. ${ }^{66}$ have shown in monkeys that stimulation of the posterior hypothalamic nuclei after vagotomy leads to gastric secretion after a latent period of three to four hours. This secretion is abolished by bilateral adrenalectomy. Hypoglycaemia after vagotomy produces gastric secretion after a similar latent period. Shay and $\operatorname{Sun}^{69}$ have shown in one patient that this late response to hypoglycaemia also disappears in man after adrenalectomy. These observations suggest that the adrenal may play a role in normal gastric physiology, and possibly also in disease.

The action of pharmacological doses of corticosteroids is undecided and many conflicting reports have appeared. There is suggestive clinical evidence that corticosteroids can cause peptic ulcers or aggravate existing ulcers; controlled data are scanty. The situation in most reports is confused because the patients are being treated for serious diseases, which in themselves may affect the stomach, and are receiving other drugs such as aspirin which may play a part in causing ulceration. Indirect evidence is available from three Medical Research Council trials of cortisone (the dose varied from patient to patient: the maintenance dose was generally around $100 \mathrm{mg}$. daily and the duration of treatment varied from six weeks to two years) in the treatment of rheumatoid arthritis, ${ }^{60,61}$ asthma ${ }^{62}$ and ulcerative colitis. ${ }^{78}$ One peptic ulcer was observed among 188 patients treated with cortisone and no ulcer among 179 patients who received control treatment (aspirin in patients with arthritis). In a comparative therapeutic trial of corticotrophin and cortisone in ulcerative colitis, ${ }^{79}$ more patients showed signs of hypercortisonism after treatment with corticotrophin, 80 units daily for six weeks, than after treatment with cortisone, $200 \mathrm{mg}$. daily for the same time. Two peptic ulcers, of which one perforated and the other bled, occurred among those treated with corticotrophin. It seems likely that large doses of corticosteroids can cause peptic ulcers or aggravate a pre-existing ulcer; it is doubtful if this is a complication when smaller doses are used.

Not only is the clinical evidence confused but experimental observations on human gastric secretion during corticosteroid therapy are difficult to interpret, often because serial observations are made as a patient is recovering from a disease. Observations made in this way suggest that large doses of corticosteroids increase gastric secretion. ${ }^{9,}, 34$ In normal subjects, prednisone, $30 \mathrm{mg}$. daily for one week or 15 to $20 \mathrm{mg}$. daily for four weeks, did not appear to influence basal gastric secretion. ${ }^{5}$ Short-term infusions of corticotrophin and various steroids at different times in normal subjects produced no unequivocal change in the output or concentration of acid or pepsin undef basal conditions, though the viscosity of the juice fell significantly during corticotrophin and corti costerone infusion but not during hydrocortisoneinfusion. ${ }^{38}$ The secretion of acid from a Heiden hain pouch in dogs was increased by pharmaco? logical doses of corticotrophin, cortisone, methy prednisolone and aldosterone..$^{15}$ The viscosity of the juice secreted under basal conditions from the pouches decreased during treatment. If large doses of corticosteroid drugs do favour peptio ulceration, as seems likely, the mechanism is un $\overrightarrow{0}$ decided. It may be by increasing gastric secretion of acid and pepsin, by altering the secretion ow properties of mucus, by altering the inflammators response of the tissues, or by a combination of these factors.

The role of the pancreas in peptic ulceration ha received much attention since Zollinger and Ellison ${ }^{85}$ described two cases of gastric hyper - secretion with intractable peptic ulceration assoN ciated with non-insulin-secreting adenomas of the pancreas. At least 75 such cases with pancreatic adenomas have now been reported $^{84}$ and 15 of these patients also had functioning adenomas in other endocrine glands. Hyperplasia of isles tissue may also cause the syndrome. ${ }^{72}$ Thes patients secrete large quantities of acid gas gic juice under basal conditions and at night (20 3 litres); the basal secretion may be almost as geep as the 'maximal' histamine-response. ${ }^{72}$ Remo of a pancreatic adenoma, containing a 'gastrin like substance', without interference with the stomach has recently resulted in clinical cure with a substantial reduction in nocturnal gastrie secretion. ${ }^{37,} 67$

It was at first suggested that the active substance produced by the pancreatic adenomas might beglucagon. Glucagon has now been shown tक reduce gastric secretion in $\operatorname{man}^{62 a}$ and in animals. Insulin, by producing hypoglycaemia, stimulates gastric secretion. Prolonged observation reveals that there is an immediate response and then $\overrightarrow{\mathfrak{X}}$. delayed response after several hours. ${ }^{69,71}$ The immediate response is probably mediated by the vagus nerves; the delayed response is humoralo possibly mediated via the adrenal glands ${ }^{69}$ or by another mechanism. ${ }^{19}$ These observations sugges? that insulin and glucagon may be important in normal gastric physiology and in disease.

An association between peptic ulceration, pan $\tilde{O}$ creatic adenomas and functioning adenomas ir other endocrine glands has already been mene tioned. An association between peptic ulceratioß and parathyroid adenomas has also been reported. The 'multiple adenoma' syndrome, in which adenomas arise in different endocrine glands ino 
the same patient, has recently received much attention. Any association this syndrome may have with peptic ulcer is as yet unexplained.

\section{Defensive Factors}

Less seems to be known about the factors which protect the gastro-intestinal mucosa from injury than about the forces which attack it. The covering layer of mucus is one obvious defensive feature and the ability of erosions to heal is another. These topics, as far as they concern the stomach, have been well reviewed by James. ${ }^{46}$ The physical state of gastric mucus depends on the acidity of the medium in which it is suspended. When the acidity is less than $\mathrm{pH} 5.2$ mucus forms a colloidal suspension; when the acidity is greater than this mucus coagulates and no longer contributes to the viscosity of the suspending fluid. The epithelial cells of the mucosa contain mucus and form an intra-cellular layer of mucus in addition to the layer of mucus adherent to the surface. These cells tend to be shed during digestion and are rapidly replaced, probably from the gastric pits. This process is not normally associated with any inflammatory response and is probably a defensive mechanism. Mucus has been separated chemically into a number of fractions but their identity and role are not yet clearly defined.

Observations on gastric secretion suggest that an alkaline ' non-parietal' component is usually present, probably secreted by the surface mucus cells and the mucus cells at the neck of the gastric glands. On theoretical grounds, it can be calculated that 3.8 parts of non-parietal component neutralize I part of parietal component. ${ }^{42}$ The classical observations of Wolf and Wolff, ${ }^{83}$ on their subject, Tom, showed that the $\mathrm{pH}$ of the stomach wall might lie between $\mathrm{pH}_{4}$ and 7 , due to the out-pouring of alkaline mucus, even when the stomach had recently been secreting acid and the pool of gastric juice was more acid than $\mathrm{pH} 2$. In this subject with a gastric fistula, interference with the mucus layer during prolonged exposure of the mucosa to acid led to ulceration. On some occasions a very high rate of acid secretion was noted without a concurrent increase in secretion of mucus. The authors suggest that this disparity may be potentially dangerous. In this connection, the fall in viscosity of gastric juice after corticosteroid administration, discussed above, is of interest. Johnson ${ }^{48}$ has shown that in vitro acid penetrates gastric mucus very slowly. It seems likely that any factor which interferes with the constant replenishment of the mucus lining of the stomach and duodenum would favour ulceration.

\section{Special Features of Gastric, Duodenal and Jejunal Ulcers}

It has already been pointed out that, as a group, patients with gastric ulcer differ from patients with duodenal ulcer. Gastric ulcers tend to occur in an older age group than duodenal ulcers, they are commonest in the lowest social class whereas duodenal ulcer is equally distributed among the classes, they are not associated with the gastric hypersecretion typically seen in duodenal ulcer, nor are they so strongly associated with blood group $O$. These and other differences between the two types of ulcer, together with the fact that ulcers at one or other site tend to run in families, suggest that gastric and duodenal ulcers have different causes.

Chronic peptic ulcers can be produced in dogs by giving repeated injections of histamine in beeswax, a method of producing prolonged secretion of acid. About $70 \%$ of these ulcers occur in the first part of the duodenum and $30 \%$ in the gastric antrum. ${ }^{17}$ As a group, patients with duodenal ulcer secrete more acid than normal, though there is considerable overlap with the normal range. A few patients with duodenal ulcer secrete two to three times more acid than the greatest secretion observed in normal subjects. In such patients as these, and probably in most patients with duodenal ulcer, it seems reasonable to ascribe the ulcer mainly to gastric hypersecretion. The fact that some patients secrete normal amounts of acid indicates that other factors must also play a part. Further investigation into the association of duodenal ulcer with blood group $\mathbf{O}$ and non-secretion of blood group substances in the digestive secretions may advance our knowledge in this respect.

Although the differences between gastric and duodenal ulcer are very real, it has become apparent that up to about $30 \%$ of gastric ulcers follow a duodenal ulcer, where:ss the reverse sequence is uncommon. ${ }^{1,57}$ It has also been observed that when the gastric ulcer appears, the duodenal ulcer has often healed.47, 74 Marks and Shay ${ }^{58}$ suggest that these patients begin by secreting excess acid and a duodenal ulcer forms; the hypersecretion also causes antral gastritis, a usual feature in patients with duodenal ulcer, ${ }^{56}$ and a gastric ulcer forms in the pyloric mucosa; a spreading gastritis ensues, acid secretion decreases and the duodenal ulcer heals.

Johnson $^{49}$ divides gastric ulcers into those occurring alone (Type I), those occurring with duodenal ulcer (Type 2) and prepyloric ulcers (Type 3). There is much to commend this division. The situation in relation to the border between gastric and pyloric mucosa, of gastric ulcers occurring alone and of those associated with 
duodenal ulcer tends to differ as already described. The acid secretory pattern also differs; ${ }^{49,58}$ patients with gastric ulcers occurring alone secrete acid poorly, those with gastric ulcers associated with duodenal ulcer or with prepyloric ulcer secrete normal or excessive amounts of acid.

If gastric ulcers occurring in the pre-pyloric rcgion and gastric ulcers associated with duodenal ulcer are assumed to be mainly the result of gastric hypersecretion, the gastric ulcers occurring alone near the border of fundic and pyloric mucosa remain unexplained. Their constant association with widespread gastritis suggests that the defensive element may be weak. The association of these ulcers with poverty and with increasing age may be important in this respect.

Ulceration of the jejunum was the presenting feature of the original cases described by Zollinger and Ellison. ${ }^{85}$ Other cases have been described since and in one of them Summerskill ${ }^{72}$ showed that samples of intestinal contents were highly acid, suggesting that the alkaline duodenal juices were inadequate to neutralize the large volume of acid continuously secreted by the stomach. Jejunal ulcer may also develop as a complication after gastro-enterostomy or partial gastrectomy. Investigation of these patients ${ }^{9}$ has shown that the ulcers are usually associated with a 'maximal' histamine response by the stomach which is greater than that of the normal intact stomach. Recurrent ulcers within the stomach, that is proximal to the line of anastomosis, on the other hand, tend to be associated with a low secretion of acid.

\section{The Present Basis of Medical Treatment*}

At the present time the medical treatment of all forms of peptic ulcer is unsatisfactory. Remission of symptoms and, sometimes, healing can be obtained, but very often symptoms re-occur at a later date. During recent years various treatments have been investigated and these will now be briefly reviewed.

(I) Rest. In a series of patients with gastric ulcer, half treated with bed-rest in hospital for four weeks and the other half treated as outpatients, the results in those treated in hospital were significantly better than in those treated as out-patients. ${ }^{24}$

(2) Sedation. Truelove ${ }^{80}$ has shown that simple sedation with phenobarbitone does not influence the outcome in patients with duodenal ulcer.

(3) Diet. Special diets do not appear to influence the rate of healing of either gastric or duodenal ulcers. ${ }^{25,26,80} \mathrm{Nicol}^{63}$ has shown that the mean

* Surgical treatment is described by Mr. Burge on page 749 . acidity of gastric samples withdrawn at half-hou intervals was greater when patients took smalp hourly sloppy feeds than when they took a more normal diet. A similar result was found when the gastric acidity of patients with duodenal ulcer: taking hourly drinks of a milk-cream mixture wass compared with the acidity when the patients took a light diet. ${ }^{6}$ These results are probably due to the rapidity with which small liquid feeds leave the stomach.

(4) Tobacco. In a series of smokers with gastric ulcer treated in hospital, the results in those who ${ }_{-}^{\circ}$ accepted advice to stop smoking were better than $\overrightarrow{0}$ in those not advised to stop smoking or who were advised to stop smoking but responded by only reducing their tobacco consumption. ${ }^{27}$

(5) Anti-secretory Drugs. Although these drugs 3 depress gastric secretion under experimentalic conditions, little evidence has been adduced that they usefully decrease gastric acidity under conditions of clinical use (Fig. 4). Clinical experience of these drugs has been disappointingN and controlled clinical trials have so far failed to음 prove their worth. ${ }^{31}$

(6) Antacids. Single doses of antacids given as liquids reduce gastric acidity for only a short time because the drug rapidly leaves the stomach. To 3 be effective, antacids must be given continuously. This may be achieved either by giving the antacid in the form of a tablet to suck or by dripping 4 to continuously through a nasogastric tube. $\Phi_{f}$. patients with duodenal ulcer suck an antacid-tablet preparation continuously between meals it is possible to keep the $\mathrm{pH}$ of the gastric contents near pH 3 throughout waking hours (Fig. 5), though nocturnal acidity remains uncontrolled. $\stackrel{\perp}{\varrho}$ The author knows of no formal therapeutic trial of $\overrightarrow{\vec{B}}$ such a regime. In patients with gastric ulcer, a 3 continuous milk drip containing sodium bicarbonate in sufficient quantity to maintain the gastric contents at $\mathrm{pH}_{3}$ throughout the 24 hours failed to influence the rate of healing of the ulcer, 25,283 . though those treated with the drip gained more weight and their pain was probably relieved more quickly than those treated without a milk drip.

(7) Anti-peptic Agents. Recently a new group of sulphated polysaccharides have been introduced $ᄋ$ which experimentally appear to protect the mucosa $D$ against the action of pepsin. ${ }^{39}$ The effectiveness of these compounds in human therapeutics has not $N$ yet been assessed but they could represent an important advance in treatment.

(8) Oestrogens. Truelove ${ }^{80}$ has recently shown $\underset{N}{N}$ that stilboestrol significantly increases the like- $\bar{O}$ lihood of healing of duodenal ulcers in men. His 0 patients were followed for five years from the end $\overparen{\varnothing}$ of treatment and those treated with oestrogens $\stackrel{\rho}{+}$ relapsed less often than the control group. This $\frac{T}{T}$ 


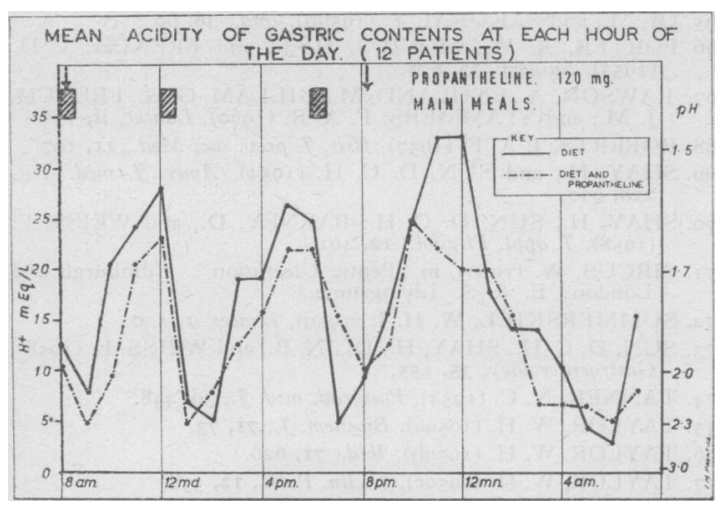

FIG. 4.-The mean acidity of hourly samples of gastric contents in 12 patients with duodenal ulcer treated with very large doses (120 mg. twice daily) of a long-acting form of propantheline bromide. There were fewer very acid samples when the drug was taken than on the control day, but the difference was small. (Bingle, and Lennard-Jones, 1960.)

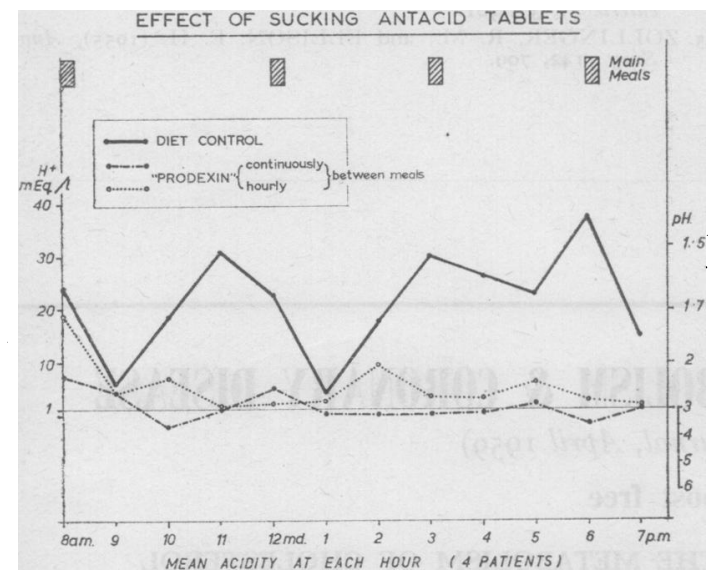

Fig. 5.-The mean acidity of samples of gastric contents at each hour of the day in four patients with duodenal ulcer who were sucking antacid tablets (aluminium glycinate 0.9 g., magnesium carbonate 0.1 g.) between meals. When one tablet was sucked each hour, starting immediately after the last sample was withdrawn, a demonstrable effect persisted one hour later. (Lennard-Jones, unpublished data.)

is a most important contribution and points the way to further developments in treatment, perhaps with non-feminizing oestrogen analogues.

It must be emphasized that all these studies concern the results of treatment in groups of patients. There is ample experimental justification for the traditional role of the physician in treating the individual patient. Emotional stresses, overwork, infrequent meals, excessive consumption of tobacco, alcohol or aspirin-all these and many other factors may need modification. At present, advice, rest and liberal antacid treatment, possibly with a milk drip, still form the basis of medical treatment. Recent studies give hope that the physician's hand may soon be strengthened by new methods of therapy.

\section{REFERENCES} I. AAGAARD, P., ANDREASSEN, M., and KURZ, L. (1959),
Lancet, i, i i i .

2. ALVAREZ, A. S., and SUMMERSKILL, W. H. J. (1958), Ibid., ii, 920. 3. BACKETT, E. M. (1960), in 'Peptic Ulceration'. Edinburgh
and London: E. \& S. Livingstone.

4. BARRETT, N. R. (1950), Brit. F. Surg., 38, 175.

5. BECK, I. T., FLETCHER, H. W., MCKENNA, R. D., and GRIFF, H.' (1960), Gastroenterology, 38, 740.

6. BINGLE, J. P., and LENNARD-JONES, J. E. (1960), Gut (in course of publication).

7. BLACK, J. W., FISHER, E. W., and SMITH, A. N. (1958a), F. Physiol., I4I, 27.

8. BLACK, J. W., FISHER, E. W., and SMITH, A. N. (1958b), Ibid., 143, $2 \mathrm{IP}$.

9. BRUCE, J., CARD, W. I., MARKS, I. N., and SIRCUS, W. (1959), F. roy. Coll. Surg. Edin., 4, 85.

ro. CARD, W. I., and MARKS, I. N. (1960), Clin. Sci., r9, 147.

II. CHINN, A. B., BOOK, D. T., and BEAMS, A. J. (1951), Gastroenterology, 18, 427.

12. CLARK, C. G., CURNOW, V. J., MURRAY, J. G., STEPHENS, F.' O., and WYLLIE, J.' H. (1960), 'f. Physiol., I53, 6IP.

13. CLARK, D. H. (1953), Brit. med. f., i, 1254 .

14. CLARKE, C. A., EVANS, D. A. P., MCCONNELL, R. B., and SHEPPARD, P. M. (1959), Ibid., i, 603 .

15. CLARKE, S. D., NEILL, D. W., and WELBOURN. R. B. (1960), Gut, 1, 36.

16. CODE, C. F., and WATKINSON, G. (1955), f. Physiol., I30, 233.

17. CODE, C. F. (1960), Amer. J. dig. Dis., N.S., 5, 288.

18. COX, A. J. (1952), A.M.A. Arch. Path., 54, 407.

19. CREAN, G. P., HUSTON, J., and SIRCUS, W. (1958), Quoted by Bruce et al. (1959).

20. DAVIES, D. T., and WILSON, A. T. M. (1937), Lancet, ii, 1353 .

21. DOLL, R., and BUCH, J. (1950), Ann. Eugen., 15, 135.

22. DOLL, R., JONES, F. A., and BUCKATZSCH, M. (r951), 'Spec. Rep. Ser. med. Res. Coun. (Lond.)', No. 276.

23. DOLL, R., and KELLOCK, T. D. (1951), Ann. Eugen., 16, 231. 24. DOLL, R., and PYGOTT, F. (1952), Lancet, i, 171.

25. DOLL, R., FRIEDLANDER, P., and PYGOTT, F. (1956), Ibid., i, 5 .

26. DOLL, R., PRICE, A. V., PYGOTT, F., and SANDERSON, P. H. (1956), Ibid., i, 70 .

27. DOLL, R., JONES, F. A., and PYGOTT, F. (1958), ibid., i, 657 .

28. DOLL, R., SWYNNERTON, B. F., and NEWELL, A. C. (1960), Gut, 1, 31 .

29. DRAGSTEDT, L. (1959), Amer. Y. dig. Dis., N.S., 4, 834.

30. EDWARDS, F. C., and EDWARDS, J. H. (1956), Lancet, ii, 543 .

31. FRIEDLANDER, P. H. (1954), Ibid., i, 386.

32. GILLESPIE, I. E., CLARK, D. H., KAY, A. W., and TANKEL, H. I. (1960), Gastroenterology, 38, 36r.

33. GLYNN, L. E., HOLBOROW, E. J., and JOHNSON, G. D. (1957), Lancet, ii, 1083.

34. GRAY, S. J., BENSON, J. A., REIFENSTEIN, R. W., and SPIRO, H. M. (1951), Э. Amer. med. Ass., 147, 1529.

35. GREGORY, R. A., and TRACY, H. J. (1959), $\mathcal{F}$. Physiol., 149, $70 \mathrm{P}$.

36. GREGORY, R. A., and TRACY, H. J. (1960), Amer. Y. dig. Dis., N.S., 5, 308.

37. GREGORY, R. A., TRACY, H. J., FRENCH, J. M., and SIRCUS, W. (1960), Lancet, i, 1045.

38. HIRSCHOWITZ, B. I., STREETEN, D. H. P., LONDON, J. A., and POLLARD, H. M. (I957), 'Y. clin. Invest., 36, I 171 I.

39. HOUCK, J. C., BHAYANA, J., and LEE, T. (1960), Gastroenterology, 39, 196.

40. HUNT, J. N. (1951), F. Physiol., 113, 169.

4I. HUNT, J. N., and KAY, A. W. (1954), Brit. med. F., 1i, 1444.

42. HUNT, J. N. (1959), Physiol. Rev., 39, 491.

References continued overleaf. 
43. IRVINE, W. T., DUTHIE, H. L., and WATON, N. G. (1959a), Lancet, i, ro61.

44. IRVINE, W. T., DUTHIE, H. L., RITCHIE, H. D., and WATON, N. G. (1959b), Ibid., i, 1064.

45. JAMES, A. H., and PICKERING, G. W. (1949), Clin. Sci., $8,18 \mathrm{I}$.

46. JAMES, A. H. (1957), 'The Physiology of Gastric Digestion'. London: Edward Arnold.

47. JOHNSON, H. D. (1955), Lancet, i, 266.

48. JOHNSON, H. D. (1957a), Ibid., ii, 515 .

49. JOHNSON, H. D. (1957b), Ibid., ii, 518 .

50. JONES, F. A. (1957), Brit. med. F., i, 719.

51. KAY, A. W. (1953), Ibid., ii, 77.

52. KELLOCK, T. D. (1951), Ibid., ii, 1117

53. KIRSNER, J. B. (1958), Gastroenterology, 34, 145.

54. LEVIN, E., KIRSNER, J. B., PALMER, W. L., and BUTLER, C. (1948), A.M.A. Arch. Surg., 56, 345 .

55. LEVIN, E., KIRSNER, J. B., and PALMER, W. L. (195I), Gastroenterology, 19, 88.

56. MAGNUS, H. A. (1952), in 'Modern Trends in Gastroenterology', ist series. London: Butterworth.

57. MANGOLD, R. (1958), Brit. med. F., ii, 1193.

58. MARKS, I. N., and SHAY, H. (1959), Lancet, i, 1107.

59. MCARTHUR, J., TANKEL, H. I., and KAY, A. W. (1960), Gut, 1, 230.

60. MEDICAL RESEARCH COUNCIL (1954), Brit. med. F., i, 1223 .

6r. MEDICAL RESEARCH COUNCIL (1955), Ibid., ii, 695

62. MEDICAL RESEARCH COUNCIL (1956), Lancet, ii, 798. 62a. MELROSE, A. G. (1960), Gut; $1,142$.

63. NICOL, B. M. (1939), Ibid., ii, 881.

64. OI, M., OSHIDA, K., and SUGIMURA, S. (I959a), Gastroenterology, 36, 45 .
65. OI, M., and SAKURAI, Y. (1959b), Ibid., 36, 60.

66. PORTER, R. W., MOVIUS, H. J., and FRENCH, J. D? (1953), Surgery, 33, 875 .

67. RAWSON, A., ENGLAND, M., GILLAM, G. G., FRENCH J. M., and STAMMERS, F. A. R. (1960), Lancet, ii, I3I. त 68. ROBERTS, J. A. F. (1957), Brit. F. prev. soc. Med., 11, 107. 69. SHAY, H., and SUN, D. C. H. (1954), Amer. Y. med. Sci. 228, 630 .

70. SHAY, H., SUN, D. C. H., BARNEY, D., and WEISS, E (1958), f. appl. Physiol., 12, $46 \mathrm{I}$.

71. SIRCUS, W. (1960), in 'Peptic Ulceration'. Edinburgh and London: E. \& S. Livingstone.

72. SUMMERSKILL, W. H. J. (1959), Lancet, I, 120.

73. SUN, D. C. H., SHAY, H., DLIN, B., and WEISS, E. (1958) Gastroenterology, 35, 155.

74. TANNER, N. C. (1954), Postgrad. med. J., 30, 448.

75. TAYLOR, W. H. (1959a), Biochem. F., 71, 73.

76. TAYLOR, W. H. (1959b), Ibid., 71, 626.

77. TAYLOR, W. H. (1959c), \%. clin. Path., 12, 338. 78. TRUELOVE, S. C., and WITTS, L. J. (1955), Brit. med. F., $\vec{\omega}$
ii, IO4I.

79. TRUELOVE, S. C., and WITTS, L. J. (1959), Ibid., i, 387. ఫृ

80. TRUELOVE, S. C. (1960), Ibid., ii, 559.

81. WATKINSON, G., and JAMES, A. H. (195I), Clin. Sci., 10, 255.

82. WATKINSON, G. (1960), Gut, 1, 14

83. WOLF, S., and WOLFF, H. G. (1947), 'Human Gastric Function'. New York: Óxford University Press.

84. ZOLLINGER, R. M., and ELLIOTT, D. W. (1959), Gastro-N enterology, 37, 40I.

85. ZOLLINGER, R. M., and ELLISON, E. H. (1955), Ann.O Surg., J42, 709.

\section{DIETARY FAT, CHOLESTEROL METABOUISM \& CORONARY DISEASE}

(Postgraduate Medical Fournal, April 1959)

Price 6s. 6d. post free

THE EPIDEMIOLOGY OF ISCHAEMIC HEART DISEASE

B. Bronte-Stewart, M.D., M.R.C.P.

THE REGULATION OF THE HUMAN SERUM-CHOLESTEROL LEVEL

H. Gordon, M.D. (Cape Town)

THE RELATIONSHIP BETWEEN THE SERUM LIPIDS AND THE DEVELOPMENT OF ISCHAEMIC HEART DISEASE B. Bronte-Stewart, M.D., M.R.C.P.

THE COAGULABILITY OF BLOOD IN RELATION TO CORONARY HEART DISEASE

C. Merskey, M.D. (Cape), M.R.C.P. (London), and H. Lackner, M.D. (Leeds), M.R.C.P. (London)
THE METABOLISM OF CHOLESTEROL

B. Lewis, Ph.D., M.D. (Cape Town)

PRESENT CLINICAL APPLICATIONS OF DIET TO THE PREVENTION OF ISCHAEMIC HEART DISEASE

J. F. Brock, D.M., F.R.C.P.

MYOCARDIAL INFARCTION-THE COMPARATIVE RACIAL PREVALENCE IN CAPE TOWN, I957-AN ELECTROCARDIOGRAPHIC STUDY

V. Schrire, M.Sc., Ph.D., M.B., Ch.B. (Cape Town), M.R.C.P. (London and Edinburgh)

\section{ISCHAEMIC HEART DISEASE IN AFRICAN} POPULATIONS

J. F. Brock, D.M., F.R.C.P., and H. Gordon, M.D. (Cape Town)

Published by

THE FELLOWSHIP OF POSTGRADUATE MEDICINE

9, Great James Street, W.C.1 